\title{
PCR em tempo real para diagnóstico da leucose enzoótica bovina
}

\author{
Enzootic bovine leukosis real time PCR
}

\author{
Natanael Lamas Dias ${ }^{*}$ Antônio Augusto Fonseca Júnior ${ }^{I}$ Daniel Sobreira Rodrigues ${ }^{I I}$ \\ Marcelo Fernandes Camargos ${ }^{\mathrm{I}}$
}

\section{RESUMO}

O objetivo deste trabalho foi realizar a validação de uma reação em cadeia da polimerase em tempo real com o sistema Plexor ${ }^{\circledR}$ (qPCR) para o diagnóstico da Leucose Enzoótica Bovina (LEB), por meio da comparação com testes de diagnóstico recomendados pela Organização Mundial de Saúde Animal (OIE). A qPCR foi comparada com duas outras técnicas: a PCR nested (nPCR) e a imunodifusão em gel de ágar (IDGA). Das 82 amostras analisadas pela qPCR e nPCR, 79 apresentaram resultados concordantes, sendo a concordância, classificada pelo Índice Kappa, como alta. Entre as PCRs e a IDGA, o número de resultados concordantes foi de 71 e 69, respectivamente, para qPCR e nPCR, sendo a concordância classificada como considerável. A qPCR apresentou altos valores de sensibilidade e especificidade. Os valores preditivos da qPCR observados demonstraram a alta capacidade de classificação dos casos positivos e negativos. A qPCR não foi capaz de detectar três amostras positivas e tem custo ligeiramente superior que a nPCR. Entretanto, a qPCR é uma técnica mais rápida, menos susceptível a contaminações, tem alta sensibilidade, não utiliza e não gera resíduos carcinogênicos. Concluímos que a qPCR pode substituir a $n P C R$ recomendada pela OIE no diagnóstico de rotina em áreas em que a LEB é endêmica, como no Brasil.

Palavras-chave: $B L V$, validação, qPCR, nPCR, IDGA.

\section{ABSTRACT}

The goal of this research was to validate a Plexor ${ }^{\circledR}$ real time Polymerase Chain Reaction ( $q P C R$ ) for Enzootic Bovine Leukosis (EBL) diagnosis by comparison with methods recommend by the World Animal Health Organization (OIE). The qPCR was compared with two other techniques: the nested
PCR (nPCR) and to the agar gel immunodiffusion (AGID). Of 82 qPCR and nPCR analysed samples, 79 presented concordant results, being the concordance classified by Kappa Index as high. Between the PCRs and AGID, the number of concordant results was 71 and 69 , out of 82 , to qPCR and $n P C R$, respectively, being the concordance classified as considerable, in both cases. The qPCR presented high specificity and sensitivity values. The observed $q P C R$ negative and positive predictive values show that the qPCR has a high capacity to correctly classify positive and negative results. The qPCR was not able to detect three positive animals and has a lightly higher cost than the nPCR. However, the qPCR its faster, less prone to contamination, has a high sensitivity and does not use or generate carcinogenic residues. We conclude that the qPCR may be used to replace the OIE $\mathrm{NPCR}$ technique in routine diagnosis in areas where EBL is endemic, as is the case of Brazil.

Key words: $B L V$, validation, $q P C R, n P C R, A G I D$.

\section{INTRODUÇÃO}

A Leucose Enzoótica Bovina (LEB) é uma doença infecto-contagiosa de caráter crônico causada pelo Bovine Leukenia Vírus (BLV), um retrovírus, da família Retroviridae, subfamília Orthoretrovirinae, gênero Deltaretrovirus (ICTV, 2009).

Segundo a legislação brasileira (BRASIL, 2006), os animais de Centros de Coleta e Processamento do Sêmen, cujo sêmen será destinado à exportação, devem apresentar resultados negativos para LEB na

ILaboratório Nacional Agropecuário, Ministério da Agricultura, Pecuária e Abastecimento (MAPA), Av. Rômulo Joviano, s/n,. CP 50, 33600-000, Pedro Leopoldo, MG, Brasil. E-mail: natanael.dias@agricultura.gov.br. *Autor para correspondência.

"Fazenda Experimental Santa Rita (FESR), Empresa de Pesquisa Agropecuária de Minas Gerais, (EPAMIG), Prudente de Morais, MG, Brasil. 
imunodifusão em gel de Agar (IDGA) ou por ensaio imunoenzimático (ELISA) em uma amostra de soro obtida no mínimo 30 dias após a última coleta de sêmen, ou de uma amostra de sêmen processado de cada partida, por reação em cadeia da polimerase (PCR). No início de junho de 2011, a Rússia informou ao Brasil que suspenderia a importação de 89 unidades processadoras de carnes, localizadas nos Estados do Rio Grande do Sul, Paraná e Mato Grosso, dentre outras razões, alegando que a carne deveria ser oriunda de animais livres de Brucelose, Tuberculose e LEB. A Rússia importa $45 \%$ da carne bovina e $4 \%$ da carne de aves exportada pelo Brasil, o que equivaleu em 2010 a US\$ 1,999 bilhão (DIÁRIO DARÚSSIA, 2011; PORTAL DO AGRONEGÓCIO, 2011). Dentre as medidas propostas pelo Ministério da Agricultura Pecuária e Abastecimento (MAPA) para atender às exigências do governo russo, está a implantação do diagnóstico molecular da LEB em amostras oriundas de carcaças destinadas à exportação para a Rússia e que apresentem lesões compatíveis com a LEB (CAMARGOS, 2011 Informe Verbal).

Os testes de diagnóstico da LEB têm importantes aplicações na Medicina Veterinária, incluindo pesquisa, atividade de vigilância, certificação de áreas livres de doenças e estudos epidemiológicos (CAMARGOS et al, 2007). As técnicas para pesquisa de anticorpos recomendadas pela Organização Mundial de Saúde Animal (OIE) são a IDGA e o ELISA, que detectam anticorpos contra a glicoproteína do envelope viral denominada gp51. A PCR é o único teste de diagnóstico direto da LEB recomendado no Manual de Testes de Diagnóstico e Vacinas para Animais Terrestres da OIE (OIE, 2008). A IDGA foi considerada por muitos anos a prova de eleição pela sua alta especificidade, sensibilidade e por ser de baixo custo (REICHEL et al., 1998). Em algumas situações, as provas sorológicas falham na identificação dos animais infectados, por exemplo, no periparto (GENTILE et al., 1985; EBERTUS et al., 1987), em animais infectados recentemente, visto que a detecção de anticorpos ocorre no mínimo três semanas após a infecção (DE BÔER et al., 1987), em bovinos permanentemente soronegativos ou com baixos títulos de anticorpos e em animais persistentemente infectados pelo BVDV que apresentam resposta imune deprimida a infecções pelo BLV (EAVES et al., 1994; KLINTEVALL et al., 1994).

A PCR é uma técnica conveniente para detectar o DNA proviral em amostras de sangue, suspensões de órgãos e material tumoral, sendo um método sensível que permite um diagnóstico rápido e precoce (BALLAGI-PORDÁNY et al., 1992). CAMARGOS et al. (2005), ao avaliar três técnicas de diagnóstico para a LEB (IDGA, ELISA e PCR), verificou que a PCR pode ser utilizada como prova complementar às provas sorológicas. FECHNER et al. (1996) e DITTRICH (2004) observaram que a PCR e PCR em tempo real (qPCR) detectaram mais animais positivos que a IDGA e ELISA. A PCR em tempo real, quando comparada à PCR convencional, de uma forma geral, tem como vantagens o menor tempo gasto na execução do ensaio, pois torna desnecessária a realização da eletroforese para visualização dos produtos da PCR e permite o diagnóstico em um número maior de amostras por vez; diminui a chance de contaminação das amostras, pois não é necessária a manipulação dos produtos da PCR e apresenta maior sensibilidade. Além disso, o custo dos reagentes tem diminuído a cada ano (KUBISTA et al., 2006).

A validação de métodos pode envolver: o uso de método normalizado, previamente validado por meio de estudos colaborativos; pela comparação do desempenho do método em validação com a obtida por um método de referência reconhecido (oficial ou padrão internacional) e adequadamente documentado; o uso de materiais de referência; e a documentação do desempenho do método por meio de participações em ensaios de proficiência (MAC NEIL et al., 2000; ABNT NBR ISO/IEC 17025, 2005).

Portanto, o objetivo deste trabalho foi realizar a validação de uma qPCR com o sistema Plexor ${ }^{\circledR}$ para o diagnóstico da LEB, por meio da comparação com testes de diagnóstico recomendados pela OIE.

\section{MATERIAL E MÉTODOS}

Foram colhidas 82 amostras de sangue bovino de animais adultos de quatro rebanhos leiteiros do Estado de Minas Gerais, sendo um dos rebanhos livre da doença. A quantidade de amostras utilizadas no estudo baseou-se nas informações descritas por ESPY et al. (2006) e BURD (2010). A extração de DNA foi realizada de acordo com protocolo descrito por FONSECA JUNIOR et al. (2010) com alterações. Em $100 \mu \mathrm{L}$ de papa de leucócitos, foram adicionados $50 \mu \mathrm{L}$ de proteinase $\mathrm{K}\left(10 \mathrm{mg} \mathrm{mL}^{-1}\right), 100 \mu \mathrm{L}$ de SDS $10 \%$ e $300 \mu \mathrm{L}$ de tris EDTA(TE). Essa solução foi homogeneizada e incubada a $56^{\circ} \mathrm{C}$ por 12 horas. Após a incubação, adicionou-se $200 \mu \mathrm{L}$ de fenol saturado e realizou-se a homogeneização e centrifugação $\left(2.000 \mathrm{~g} 5 \mathrm{~min}^{-1}\right)$. A fase aquosa foi transferida para um novo tubo e adicionouse a esta $200 \mu \mathrm{L}$ da solução de clorofórmio/álcool isoamílico na proporção de $24: 1$, esta nova solução foi homogeneizada e centrifugada conforme descrito acima. A fase aquosa foi colocada em um novo tubo e adicionada a esta duas vezes o volume obtido com 
etanol 95\% e 0,1 vezes o volume com acetato de amônio (M pH 5,6). Esta solução foi homogeneizada e armazenada por duas horas a $-70^{\circ} \mathrm{C}$ e posteriormente centrifugada $\left(13.000 \mathrm{~g} 10 \mathrm{~min}^{-1}\right)$. O sobrenadante foi descartado e acrescentou-se ao microtubo $500 \mu \mathrm{L}$ de etanol $70 \%$, novamente realizou-se a centrifugação $\left(13.000 \mathrm{~g} 10 \mathrm{~min}^{-1}\right)$ e foi descartada a fase aquosa. Após secar o pellet, este foi eluído em $80 \mu \mathrm{L}$ de TE e armazenado a uma temperatura de $-20^{\circ} \mathrm{C}$, até a sua utilização.

As amostras foram submetidas a uma PCR para o gene normalizador da beta-actina, de acordo com o protocolo descrito por CAMARGOS et al. (2008). $\mathrm{O}$ gene env foi escolhido como alvo para a qPCR. Para definição da região de amplificação, foi realizado o alinhamento de sequências dos genes disponíveis no GenBank no programa Bioedit (HALL, 1999) e também sequências brasileiras caracterizadas por CAMARGOS et al. (2007). O programa utilizado para desenho dos primers foi o Plexor Primer Design (Promega, Wisconsin, USA). A lista de primers sugeridos pelo programa foi submetida ao programa computacional PrimerBlast (http://www.ncbi.nlm.nih.gov/tools/primerblast/) para análise in silico da especificidade. Foi utilizado o sistema plexor na qPCR com os primers PleF: FAMiso-dC)AGCAAGGCCTGATAATCAGAATCG ePle-R:AATGCTTGACCTCTCG CCTTTT, que formam um produto de $100 \mathrm{pb}$. Na padronização da qPCR, selecionou-se a concentração de 15 pmoles para os primers (IDT, Iowa, EUA) e $10 \mu \mathrm{L}$ de Plexor $^{\circledR}$ Master Mix, 2X (Promega, Wisconsin, USA), para um volume final de reação de $20 \mu \mathrm{L}$. As condições de ciclagem para as duas reações foram determinadas como $95^{\circ} \mathrm{C}$ por 5 min para desnaturação, seguido por 45 ciclos a $95^{\circ} \mathrm{C}$ por $20 \mathrm{~s}, 60^{\circ} \mathrm{C}$ por $40 \mathrm{~s}$. O termociclador ABI 7500 (Applied Biosystems, California, EUA) foi utilizado em todos os testes. A qPCR foi padronizada inicialmente com DNA extraído da linhagem celular de rim de feto de carneiro (FLK) persistentemente infectada com o BLV. A concentração de amplicons foi estimada em espectrofotômetro (Nanovue ${ }^{\circledR}$, GE Healthcare Buckinghamshire, UK). O controle positivo apresentou temperatura de melting $(\mathrm{Tm})$ entre $81^{\circ} \mathrm{C}$ e $82^{\circ} \mathrm{C}$. Para avaliar a especificidade analítica da qPCR, utilizou-se o sequenciamento do gene env, a partir do DNA das amostras de células de rim de feto de carneiro (FLK). O fragmento amplificado foi submetido à PCR de sequenciamento utilizando-se o BigDye Terminator Kit (Applied Biosystems, California, EUA), conforme instruções do fabricante. As condições de termociclagem foram as mesmas utilizadas para a amplificação dos fragmentos desta região. Para o sequenciamento, utilizou-se o equipamento $A B I$ Prism
3130 DNA Sequencer (Applied Biosystems, California, EUA). As sequências foram editadas no programa Bioedit (HALL, 1999) e então comparadas no banco de dados GenBank, através da ferramenta BLAST (ALTSCHULL et al., 1997), para verificação da similaridade em relação às sequências já depositadas.

A determinação da sensibilidade analítica ou limite de detecção (LD) foi realizada a partir de diluição de uma amostra de DNA de células FLK infectadas com BLV. A amostra foi diluída em base dez até a diluição de $10^{-6}$. O LD foi determinado como a última diluição em que todas as amostras tivessem resultado positivo. O LD foi confirmado com a repetição dessas amostras em triplicata. A nPCR foi realizada utilizando os primers e o protocolo proposto pela OIE (2008) com pequenas modificações. Amplificações eficientes e reproduzíveis foram padronizadas com um volume final de reação de $20 \mu \mathrm{L}$, sendo $10,6 \mu \mathrm{L}$ de água DEPC; $4 \mu \mathrm{L}$ de tampão $5 \mathrm{X}$ Green GoTaq ${ }^{\circledR}$ Reaction Buffer (Promega, Wisconsin, USA); $0,8 \mu \mathrm{L}$ dos primers (IDT, Iowa, EUA) (10pmol $\left.\mu \mathrm{L}^{-1}\right) ; 0,4 \mu \mathrm{L} \mathrm{dNTP} \mathrm{(Ludwig}$ Biotec, Rio Grande do Sul, Brasil) $\left(10 \mathrm{mmolL}^{-1}\right) ; 1,2 \mu \mathrm{L}$ de $\mathrm{MgCl}_{2}$ (Promega, Wisconsin, USA) $(25 \mathrm{mM}) ; 0,2 \mu \mathrm{L}$ $\mathrm{GoTaq}^{\circledR}$ DNA Polymerase (Promega, Wisconsin, USA) $\left(5,0 \mathrm{U}_{\mu} \mathrm{L}^{-1}\right)$ e $2 \mu \mathrm{L}$ de DNA.

A técnica de IDGA foi realizada utilizando gel de agarose a $1 \%$ e tampão borato com $\mathrm{pH}$ entre 8,5 e 8,7 . Os reagentes foram distribuídos alternadamente utilizando 25 microlitros dos soros a serem testados, $25 \mu \mathrm{L}$ do soro controle positivo e de antígeno na cavidade central. Os resultados obtidos na qPCR e nPCR foram comparados com os obtidos na IDGA. Esses testes foram comparados avaliando-se o grau de concordância com o Índice Kappa (http:// justusrandolph.net/kappa/). A Interpretação do Índice Kappa foi realizada segundo LANDIS \& KOCH (1977): valores de Kappa $<0$ - não há concordância; valores de Kappa entre 0-0,19 - concordância pobre; valores de Kappa entre 0,20-0,39- concordância aceitável; valores de Kappa entre 0,40-0,59 - moderada concordância; valores de Kappa entre 0,60-0,79 - concordância considerável; valores de Kappa entre 0,80-1,00 - alta concordância. Foi utilizado o teste de $\mathrm{X}^{2}$ para avaliar a sensibilidade, especificidade e valores preditivos dos testes (SOARES \& SIQUEIRA, 2002).

\section{RESULTADOS E DISCUSSÃO}

O presente trabalho trata da primeira descrição na literatura de utilização do sistema Plexor ${ }^{\circledR}$ no diagnóstico molecular da LEB. Esse sistema tem como características a alta sensibilidade, baixo custo e simplicidade de uso (GASPARIC et al., 2008). 
O controle da eficiência da extração de DNA foi obtido com a PCR para beta-actina, em que foi observada amplificação de um fragmento de 130pb em todas as amostras, demonstrando a boa qualidade do DNA extraído e a ausência de inibidores da PCR. A especificidade analítica foi confirmada por sequenciamento, no qual foi observado que a sequência dos amplicons obtidos a partir dos genes env correspondiam exatamente à sequência $\operatorname{Arg} 41$ do BLV, número de acesso no GenBank, FJ914764.

A sensibilidade analítica da qPCR foi de $10^{-6} \mu \mathrm{g}$ de DNA, inferior à descrita na qPCR para o gene pol, na qual foi possível detectar o DNA proviral em $10^{-8} \mu \mathrm{g}$ de DNA (KUCKLEBURG et al., 2003). AnPCR e qPCR apresentaram, quando comparadas, altos valores de sensibilidade, especificidade, valor preditivo positivo e negativo, e alto nível de concordância segundo o Índice Kappa. Os valores preditivos observados demonstram uma alta capacidade de classificação de amostras positivas e negativas. AqPCR não foi capaz de detectar três amostras (5\%) amplificadas na nPCR. Na qPCR com $\mathrm{Sybr}^{\circledR}$ Green desenvolvida por DITTRICH (2004), 8\% das 50 amostras soropositivas na IDGA deixaram de ser detectadas. KUCKLEBURG et al. (2003), avaliando 80 amostras e utilizando primers para o gene pol, verificaram que a qPCR com molecular beacons detectou $94 \%$ de animais positivos, enquanto a pol nPCR detectou 98\% das amostras de bovinos soropositivos em ELISA. Para tentar diminuir o número de resultados falso negativos, foram realizadas tentativas de padronização de duas outras qPCR utilizando Sybr $^{\circledR}$ Green e TaqMan ${ }^{\circledR}$, entretanto, os resultados de sensibilidade e especificidade foram inferiores aos descritos neste trabalho (Dados não apresentados).

Pelos resultados descritos na tabela 1 , é possível observar uma concordância considerável entre a nPCR, qPCR e IDGA no diagnóstico da LEB. Alguns relatos na literatura mostram que a concordância entre PCR e IDGA, pode variar de $62 \%$ (DITTRICH, 2004) a $83,3 \%$ (CAMARGOS et al., 2007). Foi observado um bovino soropositivo com resultado negativo na $\mathrm{nPCR}$ e qPCR e que 10 bovinos eram soronegativos, mas positivos na qPCR e 13 soronegativos e positivos na nPCR. As divergências observadas entre resultados pelos métodos diretos e indiretos de diagnóstico da LEB podem dar a falsa impressão de baixa especificidade da nPCR e qPCR quando essas técnicas são comparadas com a IDGA (Tabela 2), entretanto, os valores obtidos refletem um melhor desempenho dos métodos diretos no diagnóstico da LEB. A não identificação pela PCR em animais soropositivos foi
Tabela 1 - Concordância entre reação em cadeia da polimerase em tempo real (qPCR), PCR nested (nPCR) e imunodifusão em gel de ágar (IDGA) no diagnóstico da Leucose Enzoótica Bovina.

\begin{tabular}{lccc}
\hline & + nPCR & - nPCR & Total \\
\hline+ qPCR & 57 & 0 & 57 \\
- qPCR & 3 & 22 & 25 \\
Total & 60 & 22 & 82 \\
Kappa $=0,91$ & & & \\
& + IDGA & - IDGA & Total \\
+ qPCR & 47 & 10 & 57 \\
- qPCR & 1 & 24 & 25 \\
Total & 48 & 34 & 82 \\
Kappa $=0,71$ & & & \\
& + IDGA & - IDGA & Total \\
+ nPCR & 47 & 13 & 60 \\
- nPCR & 1 & 21 & 22 \\
Total & 48 & 34 & 82 \\
Kappa $=0,63$ & & & \\
\hline
\end{tabular}

constatada também por KUCKLEBURG et al. (2003), CAMARGOS et al. (2007) e RAMA et al. (2011). Esse fato pode ser explicado pela existência de um pequeno número de linfócitos infectados (EAVES et al., 1994; REICHEL et al., 1998), devido à presença destas células apenas nos órgãos (KLINTEVALL et al., 1994) ou devido à supressão da multiplicação viral em animais com altos títulos de anticorpos (JIMBA et al., 2011). A não detecção de anticorpos pela IDGA em animais positivos na PCR pode ser causada por infecção recente, sendo a colheita das amostras realizada antes da soroconversão (DE BÔER et al., 1987) ou por imunossupressão no periparto (EBERTUS et al., 1987). NAIF et al. (1992), comparando IDGA, ELISA e PCR, demonstraram que a PCR diagnostica mais precocemente a infecção do que o ELISA e a IDGA. KLINTEVALL et al. (1994) verificaram que a PCR detectou o DNA proviral em linfócitos sanguíneos no sétimo dia pós-infecção e os anticorpos foram detectados primeiro pelo ELISA a partir do 26을 dia após inoculação, enquanto que, pela IDGA, a soroconversão ocorreu em média a partir do $28^{\circ}$ dia pós inoculação.

Considerando-se os riscos de contaminação de reagentes e amostras pela manipulação dos produtos da PCR externa, a necessidade de realização de eletroforese para visualizar resultados e tempo maior gasto na nPCR para finalização do método, além dos resultados obtidos neste trabalho, conclui-se que a qPCR pode ser utilizada oficialmente no diagnóstico da LEB. AqPCR não foi capaz de detectar três amostras positivas e tem custo ligeiramente superior que a nPCR. Entretanto, a qPCR é uma técnica mais rápida, menos 
Tabela 2 - Resultados de sensibilidade, especificidade, valor preditivo positivo e negativo obtidos na comparação entre as técnicas para diagnóstico de leucose enzoótica bovina.

\begin{tabular}{lccc}
\hline & nPCR x IDGA & qPCR x IDGA & qPCR x nPCR \\
\hline Sensibilidade & 0,979 & 0,979 & 0,950 \\
Especificidade & 0,618 & 0,706 & 1 \\
Valor preditivo positivo & 0,783 & 0,824 & 1 \\
Valor preditivo negativo & 0,955 & 0,960 & 0,880 \\
\hline
\end{tabular}

Para todas as comparaçãoes, $\mathrm{o} \mathrm{X}^{2}$ apresentou $\mathrm{P}=0,001$. nPCR: reação em cadeia da polimerase nested.

IDGA: imunodifusão em gel de ágar.

qPCR: reação em cadeia da polimerase em tempo real.

susceptível a contaminações, tem alta sensibilidade, não utiliza e não gera resíduos carcinogênicos.

\section{CONCLUSÃO}

A qPCR foi validada e comparada com a nPCR e IDGA e apresentou resultados de sensibilidade e especificidade semelhante a nPCR. As técnicas moleculares apresentaram resultados superiores à IDGA. Levando-se em consideração que a LEB é endêmica no Brasil e as vantagens e desvantagens da qPCR, quando comparado com a nPCR, conforme relatado anteriormente, concluímos que a $\mathrm{qPCR}$ pode ser utilizada no diagnóstico oficial dessa enfermidade.

\section{INFORME VERBAL}

Marcelo Fernandes Camargos. LANAGRO - MG Marcelo.camargos@agricultura.gov.br (LABORATÓRIO NACIONAL AGROPECUÁRIO EM MINAS GERAIS). Endereço: Av. Rômulo Joviano, s/n. Caixa Postal 35, 50, 33600000 - Pedro Leopoldo-MG, Fone: (31) 36609600.

\section{REFERENCIAS}

ABNT NBR ISO/IEC 17025. Validação de métodos. In: Requisitos gerais para a competência de laboratórios de ensaio e calibração. Rio de Janeiro, 2005. Cap.5.4.5, p.15-16.

ALTSCHUL, S.F. et al. Gapped BLAST and PSI-BLAST: a new generation of protein database search programs. Nucleic Acids Research, Oxford, v.25, p.3389-3402, 1997.

BALLAGI-PORDÁNY, A. et al. Direct detection of bovine virus infection: practical applicability of a double polymerase chain reaction. Journal Veterinary Medicine, v.39, p.6977, 1992. Disponível em: <http://onlinelibrary.wiley.com/doi/ $10.1111 / \mathrm{j} .14390450 .1992 . \mathrm{tb} 01140 . \mathrm{x} /$ abstract? system Message $=W$ ile y + Online + Lib rary $+\mathrm{wi} 11+\mathrm{be}+\mathrm{dis}$ r u p e d $+2+\mathrm{Ju} 1 \mathrm{y}+\mathrm{from}+10-$ $12+\mathrm{BST}+$ for + monthly+maintenance $>$. Acesso em: 20 nov. 2010. doi: 10.1111/j.1439-0450.1992.tb01140.x.

BRASIL. Instrução Normativa n.8 de 10 de março de 2006. Requisitos Zoossanitários para o Intercâmbio entre os Estados partes de sêmen bovino e bubalino. Diário Oficial [da] República Federativa do Brasil, Ministério da Agricultura, Pecuária e Abastecimento, Secretaria de Defesa Agropecuária, Brasília, DF, 10 mar. 2006.

BURD, E.M. Validation of laboratory-developed molecular assays for infectious diseases. Clinical Microbiology Reviews, v.23, n.3, p.550-576, 2010. Disponível em: <http:/ /cmr.asm.org/cgi/content/short/23/3/550>. Acesso em: 20 set. 2011. doi: 10.1128/CMR.00074-09.

CAMARGOS, M.F. et al. Molecular characterization of the env gene from Brazilian field isolates of Bovine leukemia virus. Virus Genes, v.34, n.3, p.343-350, 2007.

CAMARGOS, M.F. et al. Evaluation of diagnostic tests to bovine leukemia vírus. Revista Portuguesa de Ciências Veterinárias, v.102, p. 169-173, 2007.

CAMARGOS, M.F. et al. Aplicação da reação em cadeia da polimerase para detecção de Mycoplasma spp na rotina de cultivos celulares. Ciência Animal Brasileira, v.9, n.3, p.786-790, 2008.

DEL FAVA, C.; PITUCO E.M. Infecção pelo Vírus da Leucemia Bovina (BLV) no Brasil. O Biológico, v.66, n.1/2, p.1-8, 2004.

DIÁRIO DA RÚSSIA. Brasil vai se submeter às exigências Russas para exportação da carne. Economia. Disponível.em: $<$ http://www.diariodarussia.com.br/economia/noticias/2011/06/ 09/brasil-vai-se\%20submeter-as-exigencias-russas-paraexportacao-da-carne/>. Acesso em: 08 jun. 2011.

DE BOER, G.F. et al. Identification of bovine leukemia virus (BLV) infected cattle by complex-trapping-blocking (CTB) ELISA employing monoclonal antibodies directed against BLVp24. Journal Veterinary Medicine, v.34, p.717-728, 1987.

DITTRICH T. R.C. Produção de reagentes para o diagnóstico da infecção pelo vírus da leucose bovina. 2004. 179f. Tese (doutorado em Processos Biotecnológicos) - Curso de Pós-Graduação em Processos Biotecnológicos da Universidade Federal do Paraná, PR.

EAVES F.W. et al. A field evaluation of the polymerase chain reaction procedure for the detection of bovine leukaemia virus proviral DNA in cattle. Veterinary Microbiology, v.39, p.313$321,1994$. 
EBERTUS, R. et al. Untersuchungen über Titerbewegungen von Antikörpen gegen das bovine Leukosevirus im Blutserum und im Eutersekret bei Kühen und Färsen im perinatales Zeitraum. Archives of Experimental Veterinary Medicine, v.41, p.732-737, 1987

ESPY, M.J. et al. Real-time PCR in clinical microbiology: applications for routine laboratory testing. Clinical Microbiology Reviews, v.19, n.1, p.165-256, 2006.

GASPARIC, M.B. et al. Comparison of different real-time PCR chemistries and their suitability for detection and quantification of genetically modified organisms. BMC Biotechnology, v.8 p.26, 2008. Disponível em: <http:// www.biomedcentral.com/1472-6750/8/26>. Acesso em: 10 out. 2011. doi: $10.1186 / 1472-6750-8-26$

GENTILE, G. et al. Beobachtungen und Ergebnisse eines in Italian gepr_ften Programmes zu Bekämpfung der enzootishcen Leukose des Rindes. Dtsch Tierarztl Wochenschr, v.92, p.357-361, 1985

FECHNER, H. et al. Evaluation of polymerase chain reaction (PCR) application in diagnosis of bovine leukaemia virus (BLV) infection in naturally infected cattle. Journal Veterinary Medicine B, v.43, p.621-630, 1996.

FONSECA JR., A.A. et al. PCR duplex para diferenciação de amostras vacinais e selvagens do vírus da doença de Aujeszky. Arquivo Brasileiro Medicina Veterinária Zootecnia, v.62, n.5. p.1259 262, 2010. Disponível em: <http://dx.doi.org/10.1590/S010209352010000500032>. Acesso em: 25 out. 2011. doi: 10.1590/ S0102-09352010000500032.

HALL, T.A. BioEdit: a user-friendly biological sequence alignment editor and analysis program for Windows 95/98/NT. Nucleic Acids Symposium, Ser., v.41, p.95-98, 1999.

INTERNATIONAL COMMITTEE ON TAXONOMY OF VIRUSES (ICTV) 2009. Virus taxonomy. Virus families not assigned to an order. Disponível em: <http://www.ictvonline.org/ virusTaxonomy.asp?version=2009>. Acesso em: 08 ago. 2011.

JIMBA, M. et al. BLV-CoCoMo-qPCR: comparison of other detection methods for BLV infection and kinetics analysis in experimental transmission of BLV in cattle. Retrovirology, v.8, Suppl.1, p.A21, 2011. Disponível em: <http:// www.retrovirology.com/content/8/S1/A21>. Acesso em: 10 out. 2011. doi: 10.1186/1742-4690-8-S1-A21.
KLINTEVALL, K. et al. Bovine leukaemia virus: rapid detection of proviral DNA by Nested PCR in blood and organs of experimentally infected calves. Veterinary Microbiology, v.42, n.2/3, p.191-204, 1994.

KUBISTA, M. et al. The real-time polymerase chain reaction. Molecular Aspects of Medicine, v.27, p.95-125, 2006.

KUCKLEBURG et al. Detection of bovine leukemia virus in blood and milk by nested and real-time polymerase chain reactions. Journal of Veterinary Diagnostic Investigation, v. 15, p.72-76, 2003

LANDIS, J.; KOCH, G.G. The measurements of agreement for categorical data. Biometrics, v.33, n.3, p.159-179, 1977.

MAC NEIL, J.D., et. al. Validation of analytical methods Providing your method is fit for purpose. In: FAJGELJ, A.; AMBRUS, A. Principles and practices of method validation. Cambridge: Royal Society of Chemistry, 2000. p. 100-107.

NAIF, H.M. et al. Early detection of Bovine Leukemia Virus by using an enzyme linked assay for polymerase chain reaction amplified proviral DNA in experimentally infected cattle. Journal of Clinical Microbiology, v.30, n.3, p.675-679, 1992.

OIE. World Organisation for Animal Health. Manual of diagnostic tests and vaccines for terrestrial animals. 5.ed. Paris, 2008. Disponível em: <http://www.oie.int/eng/normes/ mmanual/A summry.htm>. Acesso em: 13 jun. 2011.

PORTAL DE AGRONEGÓCIO. Temer intervém por fim de embargo russo. Disponível em: <http://www.portaldoagronegocio.com.br/ conteudo.php?id=56791>. Acesso em: 09 jun. 2011 .

RAMA, G. et al. Development of a real time PCR assay using SYBR Green chemistry for bovine leukemia virus detection. Retrovirology, v.8, Suppl.1, p.A17, 2011. Disponível em:<http://www.retrovirology.com/content/pdf/1742-4690-8 s1-a17.pdf.>. Acesso em: 10 out. 2011. doi: 10.1186/17424690-8-S1-A 17

REICHEL, M.P. et al. Evaluation of alternative methods for the detection of bovine leukaemia virus in cattle. New Zealand Veterinary Journal, v.46, n.4, p.140-46, 1998.

SOARES J.F.; SIQUEIRA, A.L. Introdução à estatística médica. Belo Horizonte: Coopmed, 2002. 300p. 